\title{
Investing in medical student's research: Promoting future of evidence based medicine in Nepal
}

\author{
B Basnet and A Bhandari \\ B.P. Koirala Institute of Health Sciences, Dharan, Nepal
}

\begin{abstract}
Along with clinical training, encouraging practice of Evidence Based Medicine (EBM) plays a crucial role in training tomorrow's doctors. Involvement of medical students in research activities is crucial in developing critical thinking, efficient literature-searching, and application of formal rules of evidence in evaluating the clinical literature, and publishing research to contribute to medicine. Though significant progress has been made in the recent years, the concept of student research is relatively new and less implemented in Nepal. Mandatory research in the medical curriculum, electives or dual degree programs can not only promote student research but also enhance better EBM practices among medical professionals.
\end{abstract}

Key words: Evidence Based Medicine, Medical Students, Nepal, Research.

\section{Introduction}

Medical science is constantly evolving with new discoveries and inventions that come either upon indepth study of the subject matter or out of sheer curiosity. Medical research adds huge significance to the existing knowledge and its practical applications.

It is very important for every clinical practitioner to keep up to date with the latest developments in medicine and to justify their clinical decisions with established facts and evidence. Advent of electronic media has increased awareness among people and has made medical knowledge more accessible to public at large. Evidence based medicine (EBM) de-emphasizes intuition, unsystematic clinical experience, and pathophysiologic rationale as sufficient grounds for clinical decision-making. ${ }^{1,2}$ Developing new skills in efficient literature search, analyzing clinical literature based on evidence and experience and undertaking research to contribute to the existing medical knowledge are vital to making a good physician in today's world. ${ }^{3}$

\section{Why student's research?}

It falls on the part of medical school training to develop medical research that is endogenous to the culture and relevant to the spectrum of diseases in the region. Along

Address for correspondence

Dr. Bibhusan Basnet

MBBS, B. P. Koirala Institute of Health Sciences

Email:bibhusan@nyayahealth.org with clinical training, encouraging evidence based practice plays a crucial role in preparing tomorrow's doctors. This gives an opportunity to create more responsible doctors and smooth patient doctor relationship for future generations. So it is the need of the generation to educate medical students to base their clinical judgment and decisions on established evidences and complement these decisions with their own knowledge and experience. Students need to seek for the latest available evidences in the treatment of illnesses as they prepare themselves to a career of service. This practice will not only make them better doctors but will also enable them to be able researchers in future.

The experience in research can also help improve a medical student's skills in seeking and critically appraising the medical literature, independent learning, and writing research papers. ${ }^{4,5}$ Student research can also contribute to the published output of an institution. Such exposures have potential to help students identify their future careers, establish important contacts, and also secure better residency positions. ${ }^{6}$

\section{Student's research in developed countries}

Research studies are part of the medical curriculum in developed countries such as the United States of America and Canada. Good mentoring and financial support provided for the students in such countries enable them to develop, design and carry out their research project on time and broaden their skills and knowledge in their subject of study. ${ }^{7,8,9}$ There are 
summer internship programs which are designed to enable students carry out rural health research along with clinical experience supervised by preceptors. ${ }^{10}$ Many international journals including BMJ, Lancet, PLoS medicines have been including student sections regularly. This has been a great platform for students across the world to publish the findings of their research and also write educational and motivating perspectives about the critical issues affecting health and health care.

\section{Student's research in South Asia}

Student research opportunities are limited in most SouthAsian countries as research is often not considered an integral part of the medical curriculum. Limited research infrastructure including inadequate funding, limited lab facilities, lack of mentors to guide medical students are some of the factors that affect research development in the region. ${ }^{6}$ Faculties themselves seldom engage in research owing to inadequate training in research, lack of incentives, work overload, poor pay, and minimal research demand in clinical practice from patients, fellow physicians, and policymakers. ${ }^{6}$ It has been reported that $91 \%$ of interns (junior trainees) reported no research experience in a medical school in neighboring India. ${ }^{11}$ A study conducted in South Asia shows that, in developing countries like Nepal and Bangladesh where the healthcare infrastructure is very poor, financial support is the main barrier for conducting research. ${ }^{12}$ Even the funds, though relatively small allocated for research activities tend to go unused owing to the lack of interest, and inadequate knowledge in research activities or lack of good research proposals. ${ }^{12}$

Student research in South Asia is mostly dependent on national or institutional research activity. Though there has been significant increase in interest and involvement of medical students and educators in research work in the last decade, they are simply not enough. South Asia harbors a quarter of the world's population along with double burden of both communicable and noncommunicable diseases. ${ }^{13}$ The projection further explains the dire need of strengthening research capacity among fresh medical graduates to efficiently address the growing burden of both communicable and noncommunicable diseases.

\section{Where do we stand in Nepal?}

The concept of medical research including student research is relatively new and less implemented in Nepal. However, there has been some significant progress in the recent years. Few medical schools in the country have family and community diagnosis studies (CDP) in their early years of medical school which is encouraging. B. P. Koirala Institute of Health Sciences (BPKIHS), a health science university in eastern region of Nepal has adopted a curriculum where research is mandatory during fourth year of medical school. This allows students to execute all the steps of a research project, from conception to final report writing, thereby narrowing the gap between academia and practice. Several other medical centers also have encouraged research related activities in their curriculum increasing the exposure of medical students to research but they are limited to few departmental efforts, encouragement by the professors or the students with interest in research. ${ }^{13}$

Few home journals as the Kathmandu University Medical Journal, Journal of Patan Academy of Health Sciences provide separate student sections for medical students to share their ideas, discuss the issues that matters to them and publish their research work. Getting published during medical school can encourage students to pursue research activities in future. Health Renaissance, home journal for BPKIHS has added a student section to encourage student writers. This has provided medical students a platform to showcase their work and motivated them to further publish their medical research and perspectives.

Medical students in Nepal are becoming increasingly enthusiastic and involved in research as evidenced by their increasing participation at various national and international conferences. However, student research efforts have been scattered and sporadic as researches have not become an integral part of the activities of most medical schools. ${ }^{14}$ Most students concentrate on preparing for assessment tests and university examinations. The problems that student researchers face in Nepal are similar to those in other South Asian countries.

It's noteworthy that several national and international organizations have contributed to efforts on promoting research related activities in medical schools. National Health Research Council (NHRC) regularly conducts workshop and seminars including research methodology and research initiatives to train medical students in the field of clinical research. Nepal Medical Association has also been organizing trainings on statistical analysis, 
use of end notes timely. Binayatara foundation (BTF), a non-profit organization based in Chicago, Illinois has been providing financial grants for medical research in Nepal since few years ago. ${ }^{15}$ This has helped medical students complete their research projects and publish in national and international journals. NHRC also awards financial grants every year with the same purpose. Unfortunately, most of the training activities are organized targeting medical students around the Kathmandu Valley and funding sources are limited.

\section{Way forward}

Developing health research capacity can ensure better practices of EBM in Nepal. Student's involvement in medical research should start from active involvement in designing the study to critical thinking during the research process rather than just collecting the data for the principal investigator. This will encourage students to think critically and encourage active participation. It is important to make them feel that they feel themselves as a part of the team that is contributing to medicine and not just an enumerator collecting raw information. Good mentorship is a vital component of effective student research. So, timely refresher trainings for faculties and allotment of funds for research activities from the medical school can be encouraging for the mentors to spend more on clinical research.

Research infrastructure needs extensive improvement. Increasing access to internet for literature review and softwares such as up-to -date which comes with the latest evidences as of today helps students treat their patients best as they begin to work as a junior trainee .Involvement of medical students in journal clubs and pro-seminars will also boost their interest in medical research. On the other hand, it increases their interests to practice EBM.

Another significant step would be to make research involvement an obligatory part of medical schools 'curricula or to promote student research as electives during their training. Elective slots and scholarships for the interested students may encourage young researchers. Introduction of prior research experiences as one of the valuable criteria when pursuing postgraduate trainings can be an important step. Introducing dual-degree programs (MBBS-PhD, MBBS-MPH) with an extended time frame can also be very successful in our Nepalese context as in other nations. ${ }^{16}$ This will allow young investigators to pursue their research interest enthusiastically and prepare future doctors who believe and practice EBM.

\section{Acknowledgments}

We are thankful to Ms. Srijana Aryal and Ms. Agya Poudyal for their valuable comments on the manuscript. We also extend our sincere thanks to Prof Badri Prasad Badhu, BPKIHS for inspiring us to prepare this manuscript.

\section{References}

1. Sackett DL, Roseberg WMC, Gray JAM, Haynes RB, Richardson WS. Evidence basedmedicine: what it is and what it is isn't. Br Med J 1996; 312:71-2.

2. Zier K, Stagnaro-Green A. A multifaceted programme to encourage medical students' research. Acad Med 2001; 76:743-7.

3. Evidence-Based Medicine Working Group. A new approach to teaching the practice of medicine. JAMA 1992; 268:2420-5

4. Houlden RL, Raja JB, Collier CP, Clark AF, Waugh JM. Medical students'perceptions of an undergraduate research elective. Med Teach 2004; 26: 659-661.

5. Frishman WH. Student research projects and theses: Should they be a requirement for medical school graduation? Heart Dis 2001; 3:140-144.

6. Aslam F, Shakir M, Qayyum MA. Why medical students are crucial to the future of research in South Asia. PLoS Med 2005; 2(11): e322.

7. Ogunyemi D, Bazargan M, Norris K, JonesQuaidoo S, Wolf K, Edelstein R et al. The development of a mandatory medical thesis in an urban medical school. Teach Learn Med 2005; 17:363-369.

8. Davis DP, Poste JC, Kelly D. The UCSD research associate program: a recipe for successfully integrating undergraduates with emergency medicine research. J Emerg Med 2005; 28:89-93.

9. Houlden RL, Raja JB, Collier CP, Clark AF, Waugh JM. Medical students' perceptions ofnan undergraduate research elective. MedTeach 2004; 26:659-661.

10. Zorzi A, Rourke J, Kennard M, Peterson M, Miller $\mathrm{K}$. Combined research and clinical learning make rural summer studentship program a successful model. Rural Remote Health 2005; 5:401. 
11. Chaturvedi S, Aggarwal OP. Training interns in population-based research: Learners' feedback from 13 consecutive batches from a medical school in India. Med Educ 2001; 35: 585-589.

12. Sadana R, D'Souza C, Hyder AA, Chowdhury AMR. Importance of health research in South Asia. BMJ 2004; 328: 826-830.

13. Ghaffar, A ; Reddy, KS ; Singhi, M. Burden of non-communicable diseases in South Asia. BMJ 2004; 328(7443):807-10.

14. Shankar PR, Chandrasekhar TS, Mishra P, Subish $P$. Initiating and strengthening medical student research: Time to take up the gauntlet. KUMJ 2006; 4(13):135-138

15. BTF Medical Research Grant [Internet].[Cited 2013 August 1] Available from: http:// binayfoundation.org/project-medical-research-grant

16. Diez C, Arkenau C, Meyer-Wentrup F. The German medical dissertation-Time to change? Acad Med 2000; 75:861-863. 